OPEN ACCESS

Edited by:

Cordula M. Stover, University of Leicester,

United Kingdom

Reviewed by: llia Voskoboinik,

Peter MacCallum Cancer Centre,

Australia

Doryen Bubeck, Imperial College London, United Kingdom

*Correspondence:

George P. Munson

gmunson@miami.edu

${ }^{\dagger}$ These authors have contributed equally to this work

Specialty section:

This article was submitted to Molecular Innate Immunity, a section of the journal

Frontiers in Immunology

Received: 22 August 2020 Accepted: 04 January 2021 Published: 22 February 2021

Citation: Merselis LC, Rivas ZP and Munson GP (2021) Breaching the Bacterial Envelope: The Pivotal Role of Perforin2 (MPEG1) Within Phagocytes.

Front. Immunol. 12:597951. doi: 10.3389/fimmu.2021.597951

\section{Breaching the Bacterial Envelope: The Pivotal Role of Perforin-2 (MPEG1) Within Phagocytes}

\author{
Leidy C. Merselis ${ }^{\dagger}$, Zachary P. Rivas ${ }^{\dagger}$ and George P. Munson* \\ Department of Microbiology and Immunology, Leonard M. Miller School of Medicine, University of Miami, Miami, FL, United States
}

The membrane attack complex (MAC) of the complement system and Perforin-1 are well characterized innate immune effectors. MAC is composed of C9 and other complement proteins that target the envelope of gram-negative bacteria. Perforin-1 is deployed when killer lymphocytes degranulate to destroy virally infected or cancerous cells. These molecules polymerize with MAC-perforin/cholesterol-dependent cytolysin (MACPF/ CDC) domains of each monomer deploying amphipathic $\beta$-strands to form pores through target lipid bilayers. In this review we discuss one of the most recently discovered members of this family; Perforin-2, the product of the Mpeg1 gene. Since their initial description more than 100 years ago, innumerable studies have made macrophages and other phagocytes some of the best understood cells of the immune system. Yet remarkably it was only recently revealed that Perforin-2 underpins a pivotal function of phagocytes; the destruction of phagocytosed microbes. Several studies have established that phagocytosed bacteria persist and in some cases flourish within phagocytes that lack Perforin-2. When challenged with either gram-negative or grampositive pathogens Mpeg1 knockout mice succumb to infectious doses that the majority of wild-type mice survive. As expected by their immunocompromised phenotype, bacterial pathogens replicate and disseminate to deeper tissues of Mpeg1 knockout mice. Thus, this evolutionarily ancient gene endows phagocytes with potent bactericidal capability across taxa spanning sponges to humans. The recently elucidated structures of mammalian Perforin-2 reveal it to be a homopolymer that depends upon low $\mathrm{pH}$, such as within phagosomes, to transition to its membrane-spanning pore conformation. Clinical manifestations of Mpeg1 missense mutations further highlight the pivotal role of Perforin-2 within phagocytes. Controversies and gaps within the field of Perforin-2 research are also discussed as well as animal models that may be used to resolve the outstanding issues. Our review concludes with a discussion of bacterial counter measures against Perforin-2.

Keywords: pore-forming protein, MACPF/CDC family proteins, innate immune effector, phagosome, phagocyte, perforin-2/MPEG1, macrophage 


\section{INTRODUCTION}

Perforin-2 is a member of the Membrane Attack Complex, Perforin/Cholesterol-Dependent Cytolysin (MACPF/CDC) superfamily of proteins (1). Most, but not all, members of this family are pore-forming proteins (2-6). This includes lytic bacterial toxins such as pneumolysin and perfringolysin $\mathrm{O}$, as well as innate immune effectors such as complement protein C9 and Perforin-1. In the blood C9, together with other complement proteins, forms the membrane attack complex (MAC) to perforate the envelope of gram-negative bacteria $(7,8)$. Perforin- 1 is deployed when killer lymphocytes degranulate to destroy virally infected or cancerous cells $(9,10)$. These molecules polymerize into rings with inner diameters of $120-300 \AA(7,10-12)$. Pores are formed when each MACPF deploys four amphipathic $\beta$-strands through lipid bilayers to form the $\beta$-barrel of the pore.

The gene encoding Perforin-2, Mpeg1, was first described in 1995 as a highly expressed gene within macrophages (13). After noting the presence of a MACPF domain the authors proposed that Perforin-2 was likely another pore-forming protein. However, more than a decade would lapse before functional, mechanistic, and structural research would begin in earnest. It is now clear that Mpeg1 is a primordial gene present in taxa spanning sponges to humans. Its domain organization has remained little changed by evolution except in cases of gene duplication. In such cases the paralog may diverge from Mpeg1. Indeed analyses across taxa and gene families suggest Mpeg1 is the ancestor of Perforin-1 and MACPF-containing complement proteins (14). In this review we critically evaluate recent progress in the nascent but growing field of Perforin-2 research with an emphasis on its expression and function within phagocytic cells.

\section{PERFORIN-2 STRUCTURE AND CELLULAR LOCATION}

Unlike soluble Perforin-1 and C9, Perforin-2 is a type I transmembrane protein (Figure 1). In this orientation the
MACPF of Perforin-2 resides within the lumen of vesicular structures. As determined by subcellular fractionation of human macrophages, endogenous Perforin-2 colocalizes with markers of the ER, Golgi, endosomes, and phagosomes (15). A proteomic study identified Perforin-2 (referred to as MPS1 in that study) in the phagolysosome compartment of activated murine macrophages (16). Another analyzed bone marrow derived dendritic cells and reported that Perforin-2 co-resides with subunits of the phagocytic NAPDH oxidase and other antimicrobial effectors of endo/phagosomes (17). Moreover, LPS stimulation increased the abundance of Perforin-2 within those vesicles. A third proteomic study found Perforin-2 within macrophage endo/phagosomes following phagocytosis of latex beads (18). Consistent with the studies above, a Perforin-2-RFP fusion protein was shown to co-localize with phagocytosed bacteria (15). This is unlikely to be an artefact because the fusion protein was also shown to be bactericidal against phagocytosed bacteria. In aggregate these studies provide compelling evidence that Perforin-2 is trafficked to endo/phagosomes.

The transmembrane domain of Perforin- 2 is followed by a cytosolic tail; typically, of less than 40 residues. As discussed below this short cytosolic tail is involved in the intracellular trafficking of Perforin-2 (19). In addition to the loss of the transmembrane domain, Perforin-1 and C9 have also lost the P2 domain. This latter domain is conserved across taxa and to date has not been found in any gene other than Mpeg1. The function of the novel P2 domain was only recently investigated through structural and mechanistic studies (20,21). Its most prominent feature is an extended $\beta$-hairpin-stiffened by interstrand disulfide bonds-that culminates in a hydrophobic tip (Figure 2) (20). The extended $\beta$-hairpin is likely involved in the initial interactions with membranes as determined by liposome binding studies with the isolated P2 domain (20). As expected, liposome binding was abolished by deletion of the $\beta$-hairpin (20). Consistent with the composition of bacterial membranes, the P2 domain was also found to preferentially bind liposomes containing negatively charged lipids (20). Although more work is required these studies suggest that the P2 domain mediates

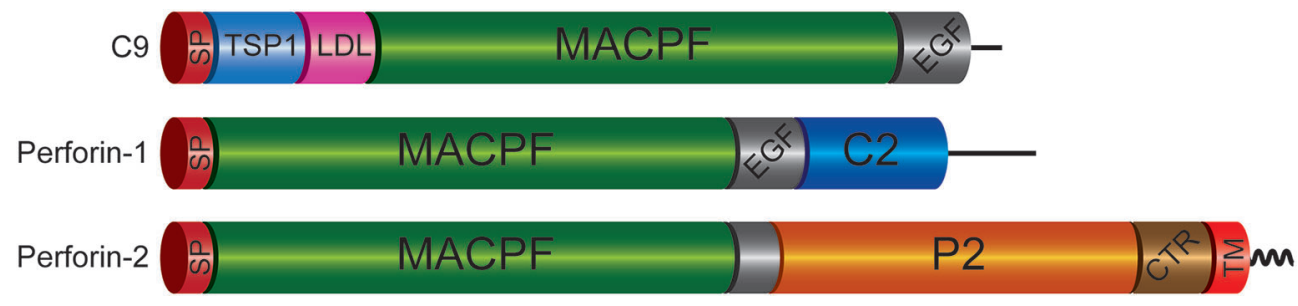

FIGURE 1 | Domain Organization of Mammalian C9 and Perforins. Each of the immune effectors contains a signal peptide (SP), membrane attack complex perforin (MACPF), and epidermal growth factor-like (EGF) domains. However, the latter is truncated in Perforin-2. The P2 domain is unique to Perforin-2 and has been evolutionarily conserved across taxa. Recent structural and functional studies suggest the P2 domain initiates contact with target membranes. However, this does not preclude other putative functions such oligomerization and/or ring stabilization. Another distinctive feature of Perforin-2 is a transmembrane domain (TM) near its carboxy terminus. Although Perforin-2 is initially a Type I transmembrane protein, it is likely cleaved from its TM domain as it is delivered to phagosomes to facilitate oligomerization and pore formation. The TM domain is followed by a short cytosolic tail that is involved in the intracellular trafficking of Perforin-2 to phagosomes. TSP1, thrombospondin type-1 repeat; LDL, low-density lipoprotein receptor class A repeat; C2, calcium-dependent phospholipid binding domain; CTR, carboxyterminal region. 


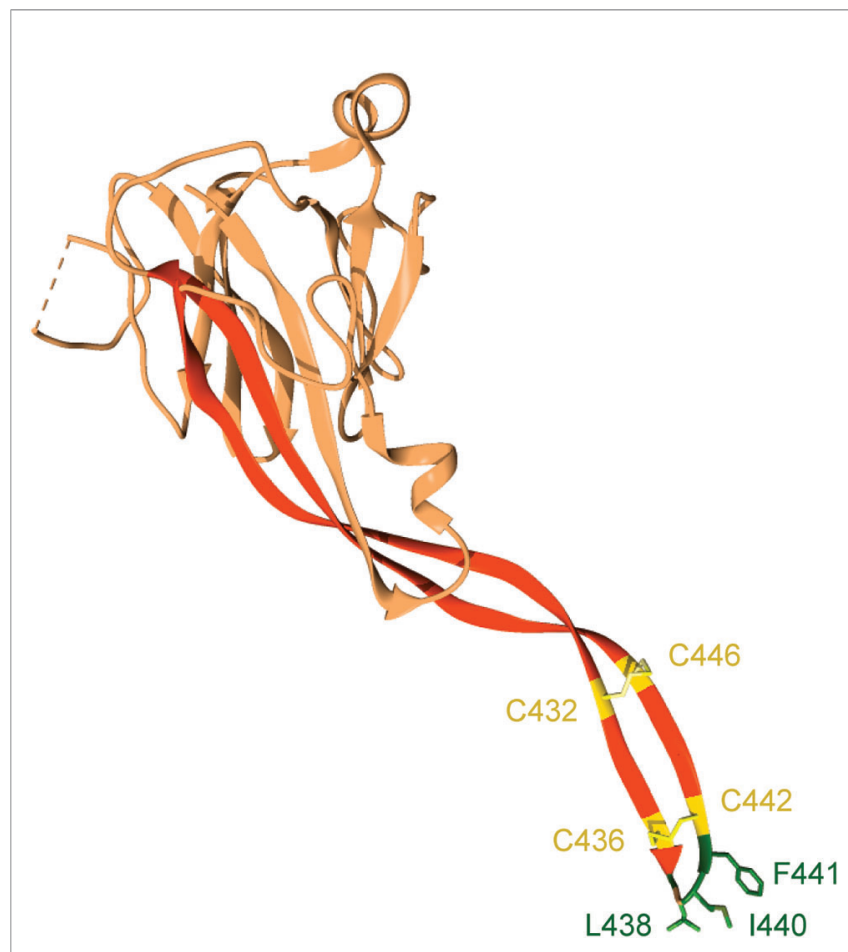

FIGURE 2 | The P2 domain of murine Perforin-2. The most prominent feature within the P2 domain is an extended $\beta$-hairpin; highlighted in dark orange. Two disulfide bonds stiffen the $\beta$-hairpin. Hydrophobic residues at the $\beta$-hairpin's tip are shown in dark green. These residues likely orient Perforin-2 on phagocytosed bacteria by initiating contact with target lipid bilayers. Numbering is relative to UniProt accession number A1L314. This graphic was rendered with UCSF Chimera from PDB file 6SB1 (http://www.rcsb.org/ structure/6SB1) (20).

Perforin-2's initial interactions with target membranes. Moreover, its extended $\beta$-hairpin may be functionally analogous to domain 4 of cholesterol-dependent cytolysins. Domain 4 contains the cholesterol binding motif as well as a signature undecapeptide at the tip of the domain that anchors the cytolysins to the target membrane $(22,23)$.

In the recently determined structures of polymerized human and mouse Perforin-2 the P2 and MACPF domains form the exterior and interior rings of the polymer respectively (Figure 3) $(20,21)$. On average these rings are composed of 16 monomers with a height of $83 \AA$ in the pre-pore conformation $(20,21)$. The pre-pore to pore transition is accompanied by a dramatic $170 \%$ increase in height as each monomer deploys its four amphipathic $\beta$-strands (Figure 3) (20). These $\beta$-strands align with each other and those of neighboring subunits to form the barrel of the pore. Acidic $\mathrm{pH}$ drives the pre-pore to pore transition $(20,21)$. This trigger is biologically relevant because it has long been established that phagosomes rapidly acidify and Perforin-2 has been shown to colocalize with phagocytosed bacteria such as Salmonella enterica serovar Typhimurium; hereafter $S$. Typhimurium $(15,24,25)$. A separate study-graphically summarized in Figure 4-found that periplasmic proteins of $S$. Typhimurium were efficiently degraded within the phagosomes of wild-type macrophages and neutrophils (26). In contrast, the degradation of periplasmic proteins was delayed within the phagosomes of Mpeg1-/- phagocytes. This was not due to differences in phagosomal proteases because a surface marker (flagellin) was efficiently degraded in both wild-type and Perforin-2 deficient phagocytes. Thus, the in situ observations are consistent with Perforin-2 pores breaching the outer membrane of $S$. Typhimurium allowing the passage of phagosomal hydrolases to the periplasmic space.

\section{PERFORIN-2 IN NON-MAMMALIAN SPECIES}

\section{Mpeg1 Expression in Invertebrates and Bony Fish}

As in other animals the innate immune responses of invertebrates and bony fish provide protection against pathogenic threats. Some of those responses involve changes within the transcriptome and pathogen or PAMP induced expression can be indicative of a gene's immunological role. Mpeg1 expression is upregulated in the sponge Suberites domuncula following LPS challenge relative to untreated animals (27). Similarly, LPS has been shown to induce the expression of Mpeg1 in the stony coral Pocillopora damicornis (28). Mpeg1 mRNA was significantly upregulated in the brain, head kidney, heart, liver, intestine, and spleen of the starry flounder Platichthys stellatus following infection with Streptococcus parauberis (29). Relative to untreated controls the expression of Mpeg1 is significantly increased when the Mediterranean mussel Mytilus galloprovincialis is exposed to heat-killed Vibrio anguillarum (30). Likewise infection of the disk abalone Haliotis discus discus with either gram-negative Vibrio parahaemolyticus or gram-positive Listeria monocytogenes induces the expression of Mpeg1 (31). Transcriptome analysis of the larvae of the eastern oyster Crassostrea virginica revealed that exposure to either the gram-negative Phaeobacter inhibens or gram-positive Bacillus pumilus induces expression of Mpeg1 (32). Similar results were observed when another species of mollusk, Haliotis midae, was challenged with live V. anguillarum (33). In the latter study increased transcription of Mpeg1 corresponded with elevated levels of Perforin-2. Of the studies discussed directly above the latter was the only one to evaluate expression at the protein level.

The genome of the orange spotted grouper, Epinephelus coioides, harbors two copies of Mpeg1. Relative to other organs both are constitutively expressed at high levels in the spleen and head kidney (34). Hematopoiesis occurs in the latter organ and it is analogous to mammalian bone marrow (35). Both copies were significantly upregulated in the spleen and gills following challenge with Cryptocaryon irritans, a protozoan parasite of significant concern to the aquaculture industry $(34,36)$. These results were subsequently confirmed by immunofluorescence with polyclonal antibodies that recognize both isoforms of $E$. coiodes Perforin-2 (37). In aggregate studies across species of invertebrates and bony fish have shown that infection and/or PAMPs induce the expression of Mpeg1. 

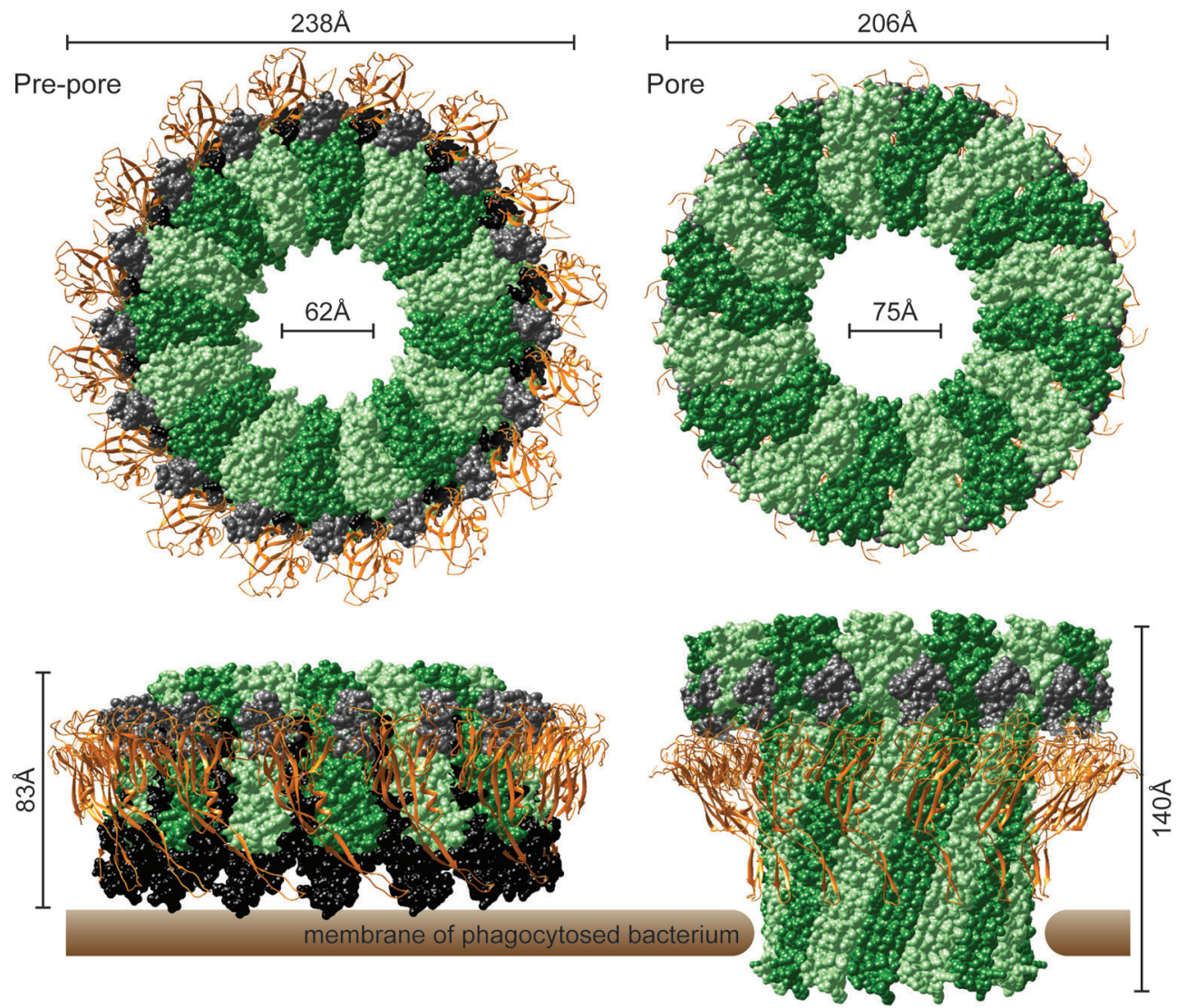

FIGURE 3 | The pre-pore and acid-dependent pore of murine Perforin-2 from top and side views. Each polymer is composed of 16 subunits. MACPF domains line the interior of each polymer and are depicted in alternating shades of green. P2 domains are depicted as orange ribbons that encircle the exterior of each polymer. A truncated EGF domain, light gray, links the MACPF and P2 domains. The carboxy-terminal region is shown in black. This region is visible in the pre-pore but was not resolved in the pore. Images were rendered with UCSF Chimera from PDB files 6SB3 (http://www.rcsb.org/structure/6SB3) and 6SB5 (http://www.rcsb.org/ structure/6SB5) (20).

Although infection or PAMP induced expression of Mpeg1 suggests Perforin-2 plays a role in host defense, Mpeg1 downregulation following bacterial infection may be indicative of bacterial countermeasures. For example, in $S$. domuncula expression of Mpeg1 is dampened by the bacterial sponge pathogen Pseudoalteromonas sp., but not the commensal bacterium Endozoicomonas sp.; species were indeterminate (38). This differential effect is suggestive of a pathogenic countermeasure deployed to defeat Perforin-2. Reduced Mpeg1 expression has also been documented in the corals Acropora cerviconis and Acropora palmata when they present with white band disease $(28,39)$. Although the etiological agent of white band disease is currently unknown, it has been suggested to be bacterial (40). Although the number of studies is few and the data preliminary, they raise the possibility that certain species of pathogenic bacteria may suppress the expression of Mpeg1 to promote colonization of invertebrates. Whether this is through stealth strategies, such as LPS modifications, or active counter measures, such as effector proteins and toxins, remains to be elucidated.

\section{Analyses of Recombinant Perforin-2 From Invertebrates and Bony Fish}

Seminal studies have reconstituted the activity of the complement membrane attack complex and Perforin-1 in vitro $(7,12,41,42)$. In recent years researchers have attempted to extend such analyses to Perforin-2. Although the P2 domain of Perforin-2 is evolutionarily conserved from sponges to humans, three studies dispensed with it to evaluate the activity of the MACPF domain from abalone, $H$. discus discus, oyster Crassostrea gigas, or flounder Platichthys stellatus (29, 31, 43). These studies reported at least some activity against gramnegative (Edwardsiella piscicida, Escherichia coli, Vibrio anguillarum, Vibrio campbelli, Vibrio harveyi, Vibrio ordalii, Vibrio tapetis, and Vibrio alginolyticus) and gram-positive (Streptococcus iniae, Streptococcus parauberis, Staphylococcus aureus, Bacillus thuringiensis, and Bacillus subtilis) bacteria. Others have examined the antibacterial effects of mostly fulllength Perforin-2; minus signal peptides, transmembrane domains and carboxy terminal residues $(27,34)$. Recombinant Perforin-2 from sponge, $S$. domuncula, was reported to have a 


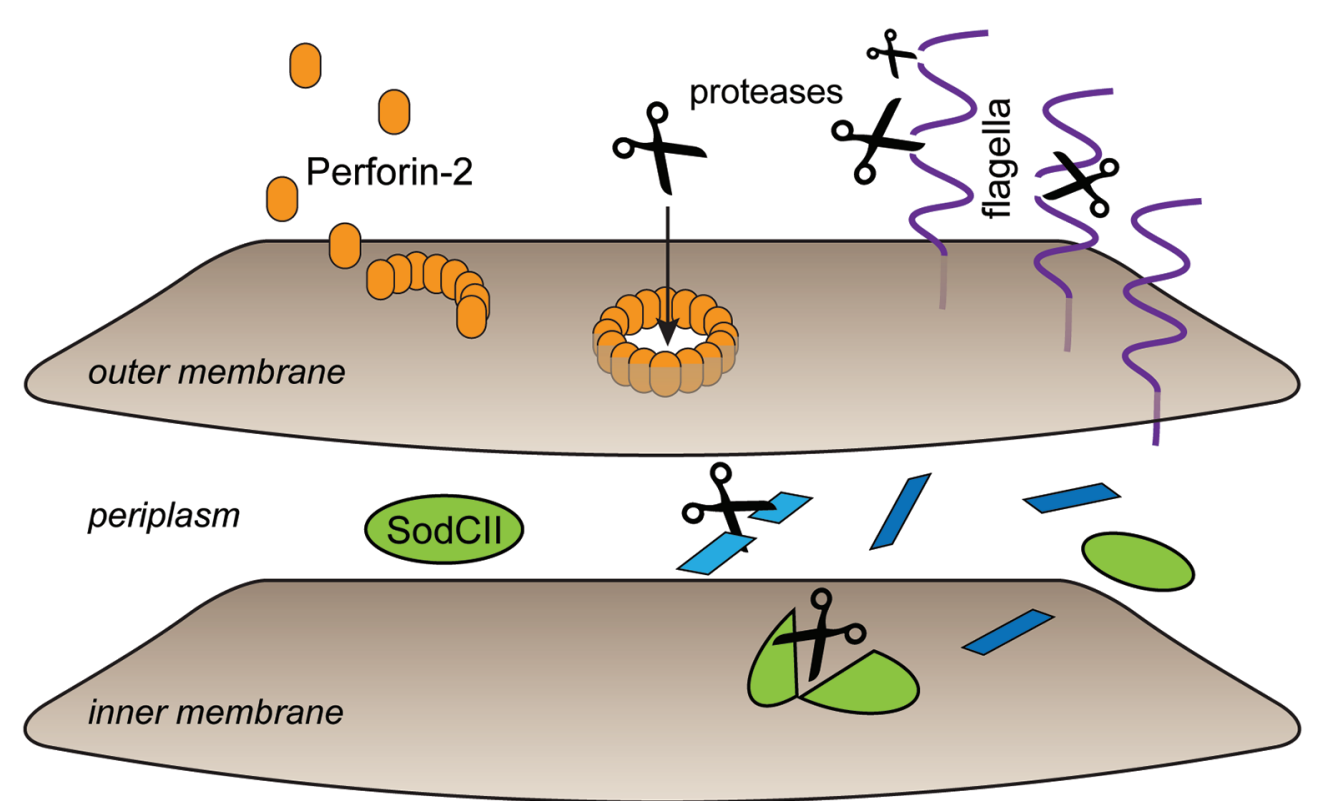

FIGURE 4 | Perforin-2 facilitates protease entry to the periplasmic space. Shortly after microbe phagocytosis Perforin-2 is delivered to the phagosome and deposits on the bacterial envelope. As the phagosome acidifies pre-pores transition to pores that breach the outer membrane. This allows proteases to enter the periplasmic space and begin the digestion of periplasmic and inner membrane proteins. In the absence of Perforin-2 phagosomal proteases are restricted to digestion of outer membrane proteins such as flagellin. This graphic is an adaptation from a previously published version (26).

negative effect upon E. coli K-12 and B; but not gram-positive Staphylococcus aureus (27). In contrast, Perforin-2a from orange spotted grouper, E. coiodes, was reported to inhibit the growth of both gram-negative and gram-positive bacteria (34). E. coiodes Perforin-2b was found to be active against only gram-positive bacteria (34). This difference is surprising because the two proteins have $90 \%$ overall identity. Nevertheless, differences were also observed when the two proteins were tested against parasitic C. irritans. Perforin-2b has no activity against $C$. irritans. In contrast Perforin-2a inhibited motility and caused rounding of theronts, the free-swimming infective form of the parasite. This rounding led the authors to speculate that Perforin-2a decreases $C$. irritans infectivity although this was not directly tested (34).

Although each of the above studies claim that recombinant Perforin-2, or its MACPF, has antimicrobial activity, each has methodological and analytical weaknesses. For example, each recombinant protein was expressed in E. coli and thus would lack their usual post-translational modifications. The MACPFs of complement protein $\mathrm{C} 9$ and Perforin-1 are known to be glycosylated (10, 44-49). Likewise, the MACPFs of Perforin-2 from sponges to humans are predicted to be $\mathrm{N}$-glycosylated at two or more Asn residues (http://www.cbs.dtu.dk/services/ NetNGlyc/). In the case of murine and human Perforin-2 these modifications have been confirmed and may play critical roles in folding and/or pore formation $(20,21,50,51)$. It is also important to point out that none of the four studies reported bacterial killing. Rather, three simply measured the optical absorbance of bacterial cultures $(31,34,43)$. The fourth did quantify CFUs but only after overnight incubation with the protein (27). Thus, in all four cases it is unknown if the reported effects are due to bacterial death or growth inhibition.

Although it is impossible to discern the mechanism(s) of the reported effects, we can deduce that pore formation was probably not involved when only the MACPF domain of Perforin-2 was used $(31,43)$. Structural studies have shown that the P2 domain is likely intrinsic to polymerization and pore formation as it forms the outer ring of both pre-pores and pores with extensive surface area contacts between adjacent P2 domains and MACPFs (Figure 3) (20, 21). Phospholipid and liposome binding studies have also revealed that the P2 domain (Figure 2) is likely required for initiating interactions with the bacterial envelope $(20,21)$. The reported activity against gram-positive bacteria is also unexpected because they are surrounded by thick layers of peptidoglycan $(27,31,34,43)$. Although Perforin-2 does kill phagocytosed gram-positive bacteria, this likely requires the assistance of phagosomal hydrolases to degrade the peptidoglycan barrier $(15,52-54)$.

\section{ANIMAL MODELS FOR PERFORIN-2 RESEARCH}

\section{Zebrafish}

Zebrafish have three Mpeg1 paralogs: Mpeg1, Mpeg1.2, and Mpeg1.3 $(55,56)$. Both Mpeg1 and Mpeg1.2 are expressed in macrophages (57). In contrast, transcriptomic studies of both larval and adult zebrafish have determined that Mpeg1.3 is a silent gene (57). Mpeg1 is under the control of the spi/pu.1 transcription factor which also regulates the expression of genes associated with myeloid 
differentiation (56). Thus, fluorescent reporters such as mCherry can be used to track macrophages in situ when the reporter is expressed from the Mpeg1 promoter (56) (Figure 5). Mpeg1.2 expression is upregulated during infection with mycobacteria, gram-negative and gram-positive bacteria (57). Curiously, the same bacterial infections inhibit Mpeg1 expression (57). This expression pattern is unlikely the result of bacterial effectors or toxins, as Mpeg1 downregulation was also observed when zebrafish were challenged with heat killed or avirulent bacteria.

Although Mpeg1 and Mpeg1.2 are inversely expressed during bacterial infections, both genes produce antibacterial responses (57). Zebrafish embryos treated with Mpeg1 specific morpholinos have increased intracellular loads of S. Typhimurium and Mycobacterium marinum relative to control morpholinos. Likewise embryos treated with Mpeg1.2 morpholinos succumb to bacterial infection significantly earlier than Mpeg1 knockdowns and controls (57). It was also observed that Mpeg1.2 has a greater antibacterial contribution than Mpeg1 which is consistent with their expression patterns during infection (57). Curiously, Mpeg1 knockdowns survive infections longer than control embryos despite greater bacterial burden. It has been proposed that Mpeg1 is a broad regulator of innate immune responses that promotes survival by diminishing lethal inflammatory responses while Mpeg1.2 is directly
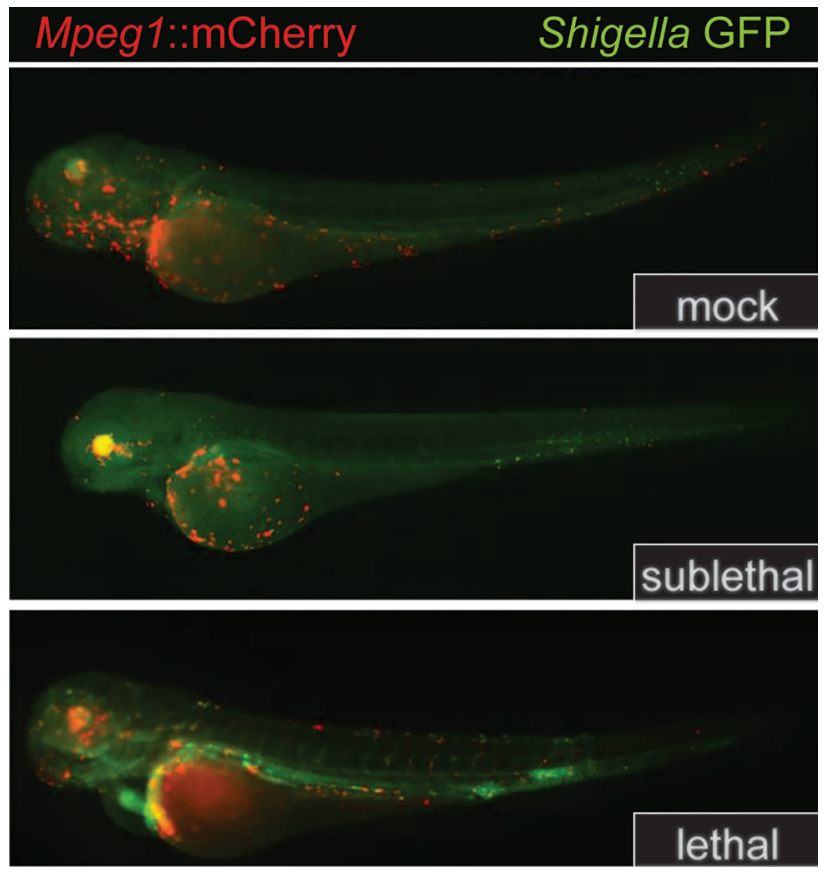

FIGURE 5 | Mpeg1::mCherry reporters facilitate the tracking of macrophages in larval zebrafish. Because the expression of Perforin-2 is largely restricted to macrophages in zebrafish, the insertion of mCherry into the Mpeg1 locus allows localization of macrophages in both fixed and live animals. The transgenic animals above were infected with sublethal and lethal doses of Shigella flexneri and fixed $24 \mathrm{~h}$ post infection. The above images have been previously published (58) and are a composite of the red and green fluorescent channels. This figure was adapted from source images posted at https://doi.org/10.1371/journal.ppat. 1003588.g002 under the CC BY 4.0 license. responsible for the bactericidal effects (57). This is surprising given that the two proteins share a common domain architecture and are $80 \%-90 \%$ identical. Additional experimentation is required to clarify the roles of Mpeg1 and Mpeg1.2 during infection.

\section{Transgenic Mice}

Eckhard R. Podack (1943-2015), in a remarkably productive collaboration with his trainee Dr. Ryan M. McCormack (59), was the first to demonstrate that mammalian Perforin-2 plays a pivotal role in the elimination of intracellular bacteria including MRSA, Mycobacterium smegmatis, and S. Typhimurium (15, 53). The Podack laboratory was also the first to report colocalization of Perforin-2 with phagocytosed bacteria (15), and interferon induced expression of Mpeg1 in keratinocytes, fibroblast and a plethora of other cell types (15). Prof. Podack was also the first to demonstrate that bacterial challenge elicits the expression of Mpeg1 in murine embryonic fibroblasts (53). Prof. Podack also coined the moniker "Perforin-2" and vigorously advocated for its usage because he understood that Perforin-2 is more descriptive of the protein's function than macrophage-expressed gene 1 protein (MPEG1) $(60,61)$. When coupled with his lifelong interest in MACPFs of the immune system (62-71), these and other foundational contributions to the field motivated Prof. Podack to commission the development of Mpeg1 knockout mice at the University of Miami Miller School of Medicine, USA. When raised under specific pathogen-free conditions these knockout mice develop normally and are phenotypically indistinguishable from their wild-type counterparts. However, in another seminal publication-and his last as sole corresponding author - Prof. Podack reported that Perforin-2 deficient mice succumb to low dose bacterial infections that most wild-type mice survive (15). As described below these results are not limited to a particular route of infection or pathogen.

\section{Orogastric Inoculation of Enteric, Gram-Negative Pathogens}

Wild-type, Mpeg1 +/- and -/- mice have been orogastrically challenged with the enteric pathogens Yersinia pseudotuberculosis and S. Typhimurium $(15,19)$. In both cases all Mpeg1 -/- mice succumbed to infection within 15 days of inoculation (Figure 6). In contrast all wild-type mice survived sublethal challenges. Heterozygous mice revealed a gene dosage effect with survival profiles between wild-type and Mpeg1 -/- mice. Perforin-2 deficiency also correlated with significantly higher loads of the pathogens in the intestines and dissemination to deeper tissues such as spleens and livers (Figure 6) (15, 19). Thus, two independent studies have demonstrated that Perforin-2 deficient mice are immunocompromised and unable to control infections that their wild-type cohorts survive $(15,19)$. These findings are further supported by in vitro studies which have demonstrated that Perforin-2 deficient phagocytes and fibroblasts are less efficient killers of intracellular bacteria than wild-type cells $(15,26,52,53,72)$.

\section{Chlamydia Intravaginal Infection}

Because phagocytes limit chlamydiae infections, investigators evaluated the role of Perforin-2 in an intravaginal infection model with Chlamydia muridarum; a gram-negative, obligate 

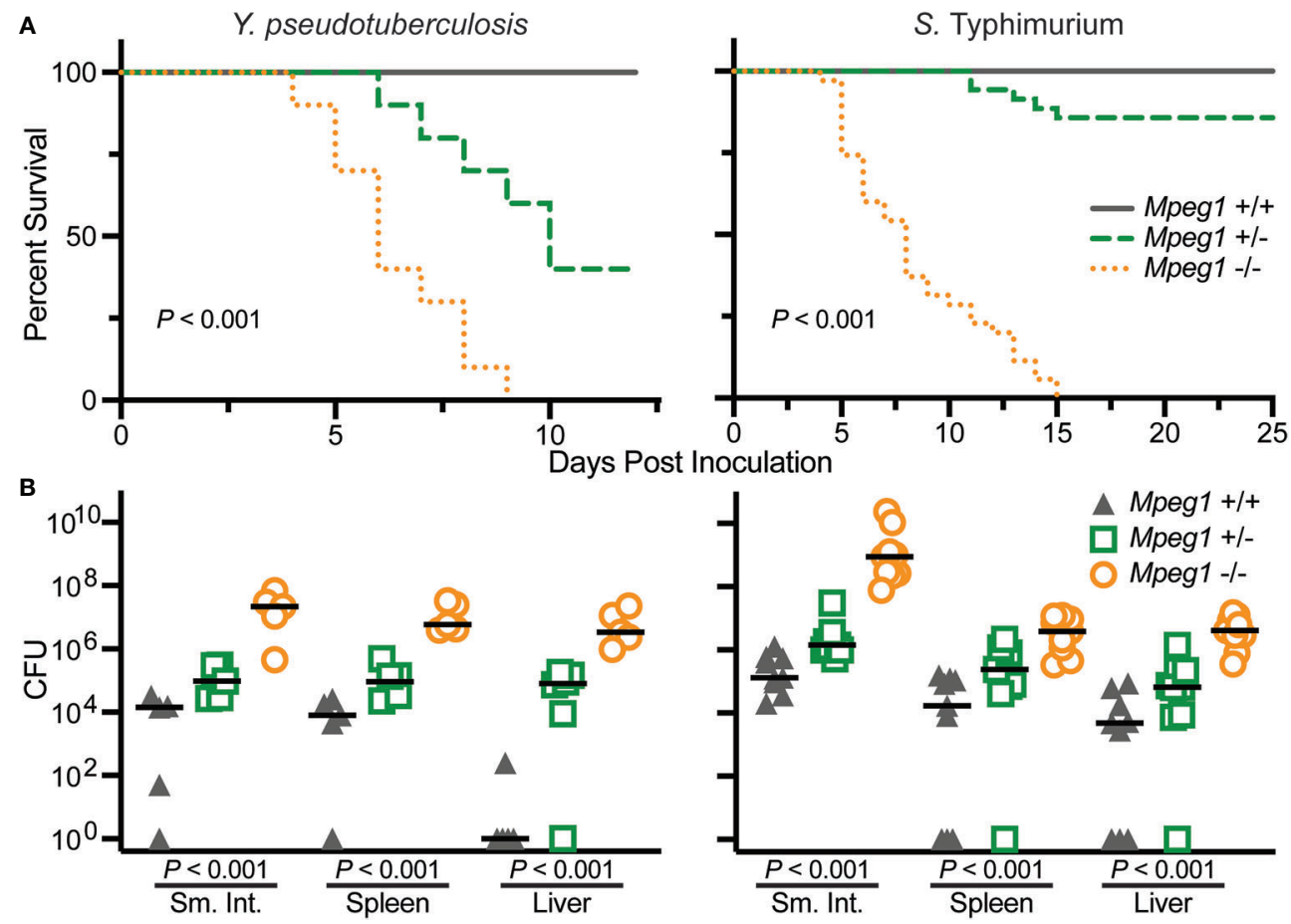

FIGURE 6 | Peforin-2 deficient mice are immunocompromised. (A) Survival curves of wild-type, Mpeg1 +/-, and -/- C57B//6 X 129X1/SvJ mice after orogastric inoculation with $10^{6} \mathrm{CFU}$ Y. pseudotuberculosis or $10^{5} \mathrm{CFU}$ S. Typhimurium. $P$ values determined by Log-rank (Mantel-Cox) test. (B) Organ loads of wild-type, Mpeg1 $+/-$, and -/- C57BI/6 $\times 129 \times 1 / \mathrm{SvJ}$ mice after orogastric inoculation with $10^{6} \mathrm{CFU}$ Y. pseudotuberculosis or $10^{5} \mathrm{CFU}$ S. Typhimurium. The former group of animals were sacrificed 10 days post inoculation while the latter were sacrificed 5 days post inoculation. Horizontal bars denote the medians. $P$ values were determined by nonparametric Kruskal-Wallis test. This figure was adapted from previously published work $(15,19)$ from source data posted at https://doi.org/10.35092/yhjc.12584993.v1 under the CC BY 4.0 license. Sm. Int., small intestine.

intracellular pathogen $(73,74)$. In addition, cell based assays had previously established that Perforin-2 limits the growth of chlamydiae in macrophages (72). In the intravaginal model Mpeg1 -/- mice exhibited significantly greater weight loss than wild-type controls and displayed other signs of morbidity such as ruffled fur (74). Surprisingly, there was no difference in the time to resolution - as determined by shedding of inclusion forming units, a quantitative indicator of infectivity and/or transmissibilitybetween the two groups. However, the researchers also observed that Perforin-2 deficient mice shed less inclusion forming units; especially, at mid-time points of the infection. To explain this conundrum the researchers speculate that $C$. muridarum may more easily ascend the genital tract and disseminate in Perforin-2 deficient than wild-type mice (74). However the experiment was not designed to test that hypothesis. Therefore, it will be necessary to revisit this model and monitor dissemination to peripheral sites to determine whether or not C. muridarum does disseminate in Perforin-2 deficient mice.

\section{Epicutaneous Infection With MRSA}

$S$. aureus is a gram-positive bacterium often present on human skin as a part of the dermal microbiome. To evaluate the role of Perforin-2 at the dermal barrier investigators shaved mice then used tape to disrupt the epidermal barrier prior to administering methicillin resistant $S$. aureus (MRSA) (15). As with other infection modalities the vast majority of infected Mpeg1 -/mice perished; although, the time to death was significantly delayed compared to the orogastric models discussed above. In contrast, ca. $80 \%-100 \%$ of the heterozygous and wild-type mice survived MRSA challenge. In another experiment the skin of Mpeg1 -/- mice contained 3 logs more MRSA than that of wildtype or heterozygous mice (15). As expected, Perforin-2 deficiency was accompanied by bacterial dissemination to the blood, spleen, and kidneys. MRSA may manipulate the transcriptome of host cells to promote its own survival because the pathogen was shown to decrease the expression of Mpeg1 in human skin cells (75). However, pretreating human skin cells with the commensal bacterium S. epidermidis prior to MRSA infection led to increased Mpeg1 expression and enhanced killing of intracellular bacteria.

\section{Intravenous Delivery of Listeria}

Perforin-2 has also been shown to aid in defense against another gram-positive bacterium, Listeria monocytogenes. Perforin-2 deficient mice infected intravenously with L. monocytogenes have significantly greater loads of the pathogen in their spleens and livers than wild-type mice (52). In a pregnancy model of infection Perforin-2 deficient mice had significantly higher loads of L. monocytogenes in both the placenta and fetuses (76). In these models injected bacteria are phagocytosed and killed by splenic and 
liver macrophages (77). But some phagocytosed bacteria escape to the cytosol where they replicate and disseminate to other cells via actin polymerization (78). To escape the phagosomal vacuole $L$. monocytogenes deploys its own pore-forming protein, the cholesterol-dependent cytolysin listeriolysin O (79). Timing is likely critical: $L$. monocytogenes must escape the vacuole before Perforin-2 delivers its lethal blow. Consistent with this hypothesis significantly more bacteria escape to the cytosol of Mpeg1 -/- than wild-type macrophages in cell based assays (52).

In the above experiments the authors also observed that phagocytosed L. monocytogenes were more likely to reside within acidic vacuoles of Perforin-2 deficient macrophages than wild-type macrophages (52). To explain this phenomenon the authors proposed that Perforin-2 limits vacuole acidification. This is controversial as to date there is no mechanistic evidence to support that hypothesis. Rather, the recent discovery that acid drives the Perforin-2 pre-pore to pore transition suggests an alternative hypothesis $(20,21)$. In our reinterpretation of the available data we propose that fewer L. monocytogenes reside within acidic vacuoles because acid activates Perforin-2 which then facilitates the destruction of vacuolar bacteria. In the absence of Perforin-2 bacteria are simply able to persist longer within acidic vacuoles. We also note that another study found that the acidification of Salmonella containing vacuoles was equivalent between wild-type and Perforin-2 deficient macrophages; see Bai et al., 2018, Supplementary Materials (26).

\section{Contradictory Signals: Perforin-2 and Type I IFN Signaling}

Although Mpeg1 is an IFN stimulated gene $(15,53)$, it has also been reported that Perforin-2 is required for Type I IFN signaling by forming complexes with IFN receptors IFNAR1 and IFNAR2 (80). The impetus for that study was the observation that Mpeg1 deficient mice are resistant to LPS induced septic shock; a model in which Type I IFNs play a central role in driving the cytokine storm. However other studies found that Mpeg1 deficient mice, on either C57BL/6 or $129 \mathrm{X} 1 / \mathrm{SvJ}$ backgrounds, are not more resistant to LPS induced septic shock than wild-type animals (81). As validation of the latter study's experimental design and outcome, both wild-type and knockout mice on the 129X1/SvJ genetic background were more resistant to LPS than C57BL/6 mice. This effect is consistent with previous studies and is due to the fact that $129 \mathrm{X} 1 / \mathrm{Sv}$ J mice lack caspase-11 $(82,83)$.

Further contradicting Perforin-2's role in Type I IFN signaling, an RNAseq study found that Type I IFN signaling is functional in Mpeg1 -/- murine phagocytes stimulated with IFN- $\beta$ (84). It is also difficult to reconcile the proposed complexes with the structures of Perforin-2 and IFNARs (20, $21,80,85)$. For example, it was reported that binding to and signaling through IFNAR1 requires glycosylation of Perforin-2 residues Asn185 and Asn269; numbering relative to UniProt entry A1L314 (https://www.uniprot.org/uniprot/A1L314) (80). Although the structures of both mouse and human Perforin-2 confirm that both residues are glycosylated, Asn185 and Asn269 reside on opposite faces of the MACPF domain (Figure 7) (20, 21). Not surprisingly, docking simulations with the known structures of IFNAR1 and Perforin-2 monomers found no plausible pathway for simultaneous binding to Asn185 and Asn 269 by IFNAR1 (86). Thus, it is not clear how IFNAR1 is able to contact both as has been proposed (80). Likewise, it has been reported that glycosylation of Asn 375 in the P2 domain is essential for interactions with IFNAR2 (80). This residue is visible in all published structures of murine and human Perforin-2 but unlike Asn185 and Asn269, Asn375 is not glycosylated (Figure 7, middle image) $(20,21)$. Although it is possible that the glycosylation pattern of Perforin-2 differs
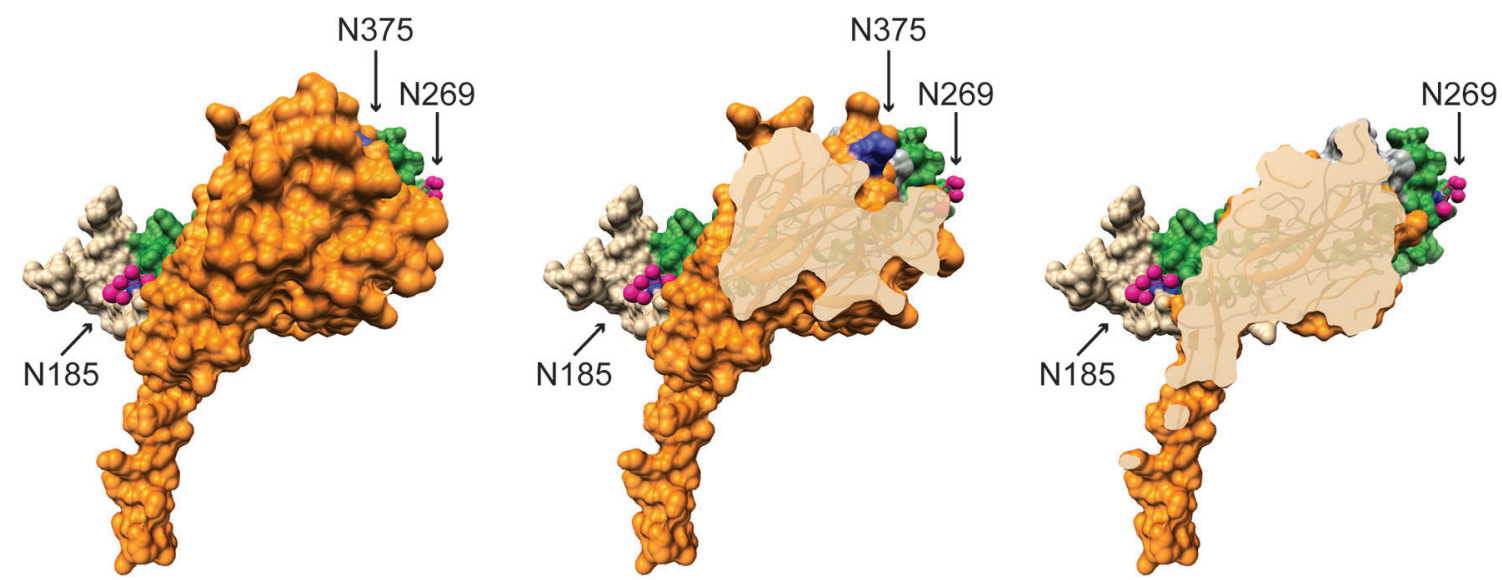

FIGURE 7 | Glycosylated Asn185 and Asn269 are located on opposite faces of the MACPF domain. A monomer of murine Perforin-2 shown in (Left) full view and (Middle \& Right) progressive cross-sections into the molecule. The MACPF and P2 domains are shaded green and orange respectively. The truncated EGF domain, which connects the MACPF and P2 domains, is shaded grey and is partially visible in the upper right of the far right image. The extended carboxy terminal region is shown in tan. Asn185 and 269 are conserved and glycosylated in both murine and human Perforin-2 (20, 21). Their glycans are shown as pink spheres. In contrast to the MACPFs, the P2 domains of both species are devoid of glycosylation. This includes the absence of glycosylation of Asn375; shaded deep blue above and visible in the middle image. Images were rendered with UCSF Chimera from PDB file 6SB3 (http://www.rcsb.org/structure/6SB3) (20). Residue numbering is relative to UniProt entry A1L314 (https://www.uniprot.org/uniprot/A1L314). 
between expression systems and cell lines, bioinformatics suggests otherwise. Like other servers, NetNGlyc identifies Asn-XSer/Thr sequons (http://www.cbs.dtu.dk/services/NetNGlyc/). However, its neural network also evaluates the surrounding sequences to predict the probability of glycosylation. In agreement with the structural studies $(20,21)$. NetNGlyc predicts glycosylation of Asn185 and Asn269 but not Asn375. In summary, the reported requirement for Perforin-2 in Type I IFN signaling and proposed mechanism (80) are challenged by transcriptomics, LPS induced sterile septic shock, and molecular analyses. Clearly additional studies are required to resolve these contradictions.

\section{PfpL, A Paralog of Murine Mpeg1}

Unlike humans, mice have a paralog of Mpeg1 named PoreForming Protein Like (PfpL, UniProt entry Q5RKV8). Over their entire length PfpL and murine Perforin-2 are 65\% identical. This suggest that $\mathrm{PfpL}$ could also function as an immune effector. However, to date there have been no functional studies of PfpL and expression of the $P f p L$ transcript appears to be more limited than that of Mpeg1 as determined by the murine gene expression database, GXD (87). Unlike Mpeg1, PfpL expression has only been observed in the context of murine development and in the adult mouse liver. Particularly high expression was also observed in a subset of trophoblast giant cells and the parietal yolk sac (88). Further experiments are needed to determine whether or not PfpL is a functional immune effector. In addition, greater clarity is required regarding the timing and location of its expression. However, the restricted expression of $P f p L$ and the clear immunocompromised phenotype of Mpeg1 knockout mice suggest $P f p L$ is at best a minor player in host defense under most circumstances.

\section{CLINICAL IMPACTS OF MPEG1 MISSENSE AND NONSENSE MUTATIONS}

The Genome Aggregation Database (gnomAD, https://gnomad. broadinstitute.org/) catalogs 432 missense (codon changes) and 23 nonsense (premature stop codon) mutations in human Mpeg1 (89). With few exceptions these mutations are heterozygous and to date only five have been functionally evaluated $(90,91)$. In one study a young adult female with a history of recurrent polymicrobial skin infections was found to have a heterozygous nonsense mutation in codon Tyr430*; numbering relative to UniProt entry Q2M385 (https://www.uniprot.org/uniprot/ Q2M385) (91). This nonsense mutation is within the extended $\beta$ hairpin of the P2 domain (Figure 8A). It is not known if this truncated protein is stably expressed. But even if it is, it is unlikely to reach endo/phagosomes because it lacks a transmembrane domain and cytosolic tail for retention and intracellular trafficking respectively. Thus, this mutation likely reduces the availability of Perforin-2 within endo/phagosomes. As expected, the ability of the patient's blood derived phagocytes to eliminate intracellular bacterial pathogens was found to be significantly impaired compared to phagocytes from healthy donors (Figure 8B) (91). This impairment is the likely cause of the patient's clinical presentations and is consistent with the gene dosage effects seen with Perforin-2 heterozygous mice after infection with a variety of pathogens $(15,19)$.

In another study three Mpeg1 missense mutations and one nonsense mutation were identified within a cohort of patients with pulmonary nontuberculous mycobacterial infections (90). T73A and P316S are within the MACPF domain while Q398* and $\mathrm{P} 405 \mathrm{~T}$ reside within the $\mathrm{P} 2$ domain (Figure 8A). All are
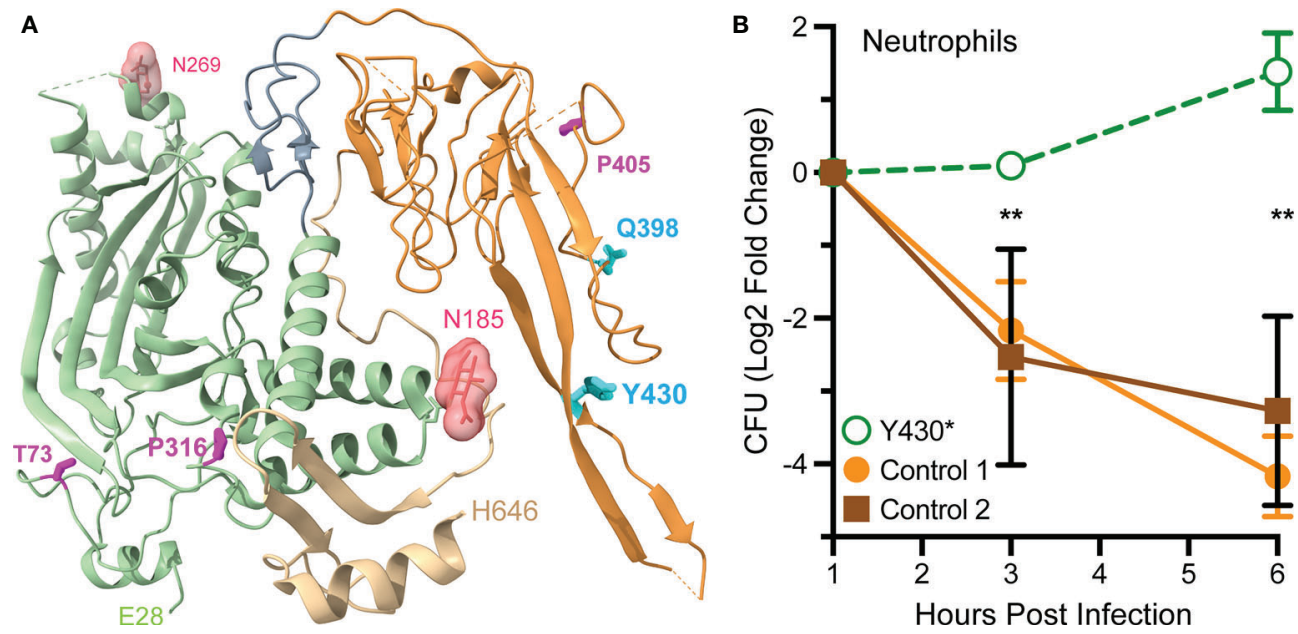

FIGURE 8 | Perforin-2 haploinsufficiency results in the reduced ability of human phagocytes to kill intracellular bacteria. (A) A monomer of human Perforin-2 in its pre-pore conformation. The MACPF and P2 domains are depicted in light green and orange respectively. The carboxy-terminal region is shown in tan. Glycans attached to N185 and N269 are shown as space filling models. Also shown are the positions of deleterious missense (magenta) and nonsense (cyan) mutations $(90,91)$. Residue numbering is relative to relative to UniProt entry Q2M385 (https://www.uniprot.org/uniprot/Q2M385). (B) Killing of intracellular S. Typhimurium by neutrophils isolated from the blood of a donor carrying a heterozygous $Y 430^{*}$ nonsense mutation or healthy controls. Relative bacterial colony forming units are reported as Log2 Fold Change $=\log 2$ (CFU at time $X)-\log 2$ (CFU at time initial). ${ }^{\star \star} P<0.01$ by 2 way ANOVA. This figure was adapted from previously published work (91) under the CC BY 4.0 license. Molecular graphics were rendered with UCSF ChimeraX from PDB file 6U2J (http://www.rcsb.org/structure/6U2J) (21). 
heterozygous and each patient presented with a history of pulmonary Mycobacterium avium complex as well as nonmycobacterial pulmonary infections. Each of the mutations are apparently deleterious because patient derived cells were less able to kill M. avium than cells from age matched controls (90). The researchers subsequently used CRISPR/Cas9 to introduce the mutations into THP-1 cells, a human macrophage-like cell line. As expected, THP-1 cells carrying the missense and nonsense mutations exhibited reduced killing capacity when infected with M. smegmatis, S. Typhimurium, and S. aureus. Based on their locations within the structures of Perforin-2 T73A and P316S may interfere with the deployment of the pore forming $\beta$-strands and pre-pore to pore transition respectively $(20,21)$. If it is stably expressed Q398* is likely secreted to the extracellular milieu because it lacks the transmembrane domain and cytosolic tail of full length Perforin-2. The impact of P405T is harder to predict as it lies in a more disordered region of the structure (21). However, it is also possible that the observed phenotypes are the result of low protein expression and/or instability since the researchers did not evaluate either (90). In the future higher resolution Perforin-2 structures and greater understanding of the mechanism of acid sensing, pre-pore to pore transition, and pore formation may facilitate testable hypotheses of the clinical impacts of Mpeg1 missense mutations.

\section{BACTERIAL DEFENSES AGAINST PERFORIN-2}

In resting cells Perforin-2 has a diffuse, perinuclear dispersal. However, it is rapidly relocated to punctate bodies upon exposure to PAMPs or infection (19). Some of these punctate bodies are likely phagosomes because Perforin-2 has been shown to co-localize with phagocytosed bacteria (15). This is consistent with a proteomic study that found Perforin-2 co-resides with subunits of the phagocytic NAPDH oxidase, proton transporters, and many other antimicrobial effectors of phagosomes (17). Other punctate bodies may be sorting endosomes in the process of delivering Perforin-2 to phagosomes because another proteomic study found Perforin-2 in endosomes following phagocytosis of latex beads by macrophages (18). LPS stimulation of bone marrow derived macrophages has also been shown to increase the abundance of Perforin-2 in endo-lysosomes compared to untreated cells (17).

The intracellular trafficking of Perforin-2 is driven by PAMPdependent ubiquitination - most likely monoubiquitinationof one or more conserved lysines in its short cytosolic tail (19). Mutagenesis of the three most conserved lysines abolished the formation of punctate bodies and Perforin-2 dependent killing of bacteria. Ubiquitination of Perforin-2's cytosolic tail was further shown to be dependent upon a cullin-RING E3 ubiquitin ligase (CRL) complex containing cullin-1 and $\beta \operatorname{TrCP}$ (Figure 9) (19). This led to the hypothesis that certain pathogens may deploy Cifs to block the intracellular trafficking of Perforin-2 because CRL activity is dependent upon the ubiquitin like molecule NEDD8 and Cifs are NEDD8 deamidases (92-96). As predicted, the researchers found that wild-type but not cif mutants of $Y$. pseudotuberculosis and enteropathogenic E. coli (EPEC) blocked the ubiquitination and intracellular trafficking of Perforin-2, as well as Perforin-2 dependent killing (19). In vivo ca. $80 \%$ of C57BL/6 mice infected with wild-type $Y$. pseudotuberculosis perished while all mice infected with a cif mutant survived (Figure 10). This difference was abolished when the two bacterial strains were used to infect Mpeg1 -/- mice. Although Cif inactivation of CRLs has broad cellular consequences, the latter results suggest that inhibition of Perforin-2 is the primary objective and most consequential effect. While Cifs are just one example of anti-Perforin-2 effectors bacterial pathogens express a multitude of effectors aimed at promoting their survival; many of which have yet to be fully characterized (97). Given that Perforin-2 is a recently described immune effector, it is reasonable to predict that other anti-Perforin-2 effectors will be discovered as the field matures.

\section{DISCUSSION}

Relative to other MACPF proteins of innate immune systems, the field of Perforin-2 research is relatively new even though the gene that encodes Perforin-2, Mpeg1, is likely the most ancient of the MACPF encoding genes (14). Nevertheless in recent years vertebrate studies have established that Perforin-2 has broad spectrum bactericidal activity that significantly limits pathogen proliferation and dissemination in vivo $(15,19,26,52-54,57,72$, 90). There is also evidence to suggest that Perforin-2 functions similarly in invertebrates; although, such studies are hampered by the lack of animal and tractable cell culture models $(27,28,30$, $31,33,38,39)$. The recent structural determinations of both mouse and human Perforin-2 polymers have further provided significant insight with regards to the mechanism(s) of pore formation (20,21). Eventually such high-resolution structures may afford greater understanding of the clinical impacts of Mpeg1 missense mutations amongst the human population.

In vitro recombinant mammalian Perforin-2 spontaneously polymerizes and one of the most significant advancements from in vitro studies was the discovery that the pre-pore to pore transition is acid dependent $(20,21)$. In retrospect the fact that low $\mathrm{pH}$ drives pore formation seems intuitive given that Perforin-2 is deployed to acidic phagosomes. Acid dependency may also be a safety mechanism, ensuring that Perforin-2 remains in a latent state so as not to damage the vesicular and cellular membranes of the phagocyte. Acid dependency likely evolved very early as lower metazoans such as sponges, corals, and mollusks have been shown to express Mpeg1 and have macrophage-like cells that phagocytose and eliminate foreign invaders through the use of lysosomal enzymes, reactive oxygen species, and cellular acidification (98-103). However, the exact mechanism of acid driven pore formation remains to be elucidated. One possibility is that acidification removes inhibitory inter- or intra-domain contacts that prevent pore formation. Clearly one of the most important objectives in this area will be to discover the acid-dependent trigger within Perforin-2. 


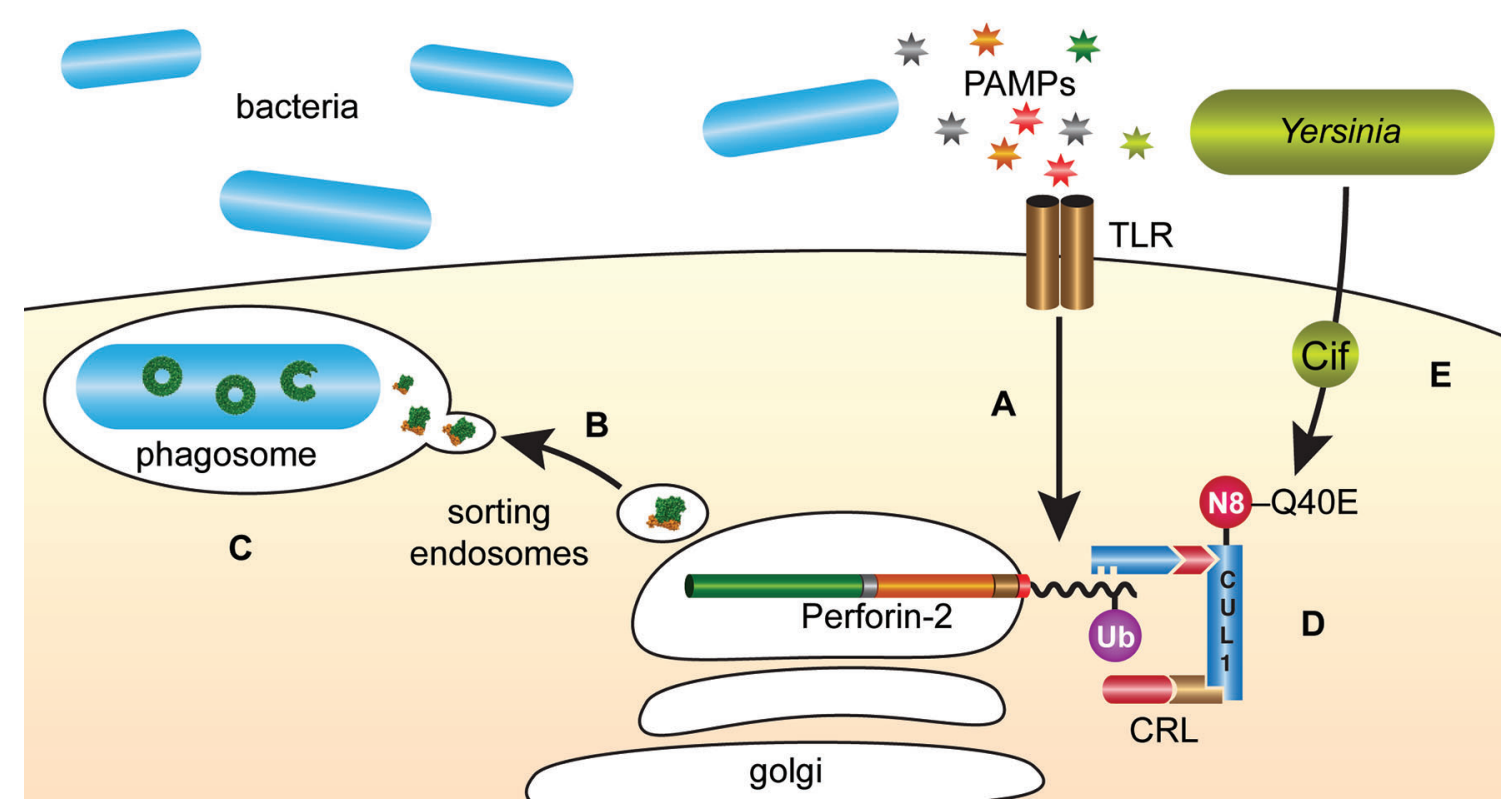

FIGURE 9 | Y. pseudotuberculosis and EPEC deploy Cifs to block the delivery of Perforin-2 to phagosomes. (A) The cytosolic tail of Perforin-2 is ubiquitinated in response to PAMPs such as LPS. (B) Ubiquitinated Perforin-2 is rapidly delivered to phagosomes where it oligomerizes and (C) phagosome acidification induces the pre-pore to pore transition. (D) The ligase responsible for conjugating ubiquitin to Perforin-2 is a multi-component cullin-RING E3 ubiquitin ligase (CRL) whose activity is itself dependent upon cullin neddylation. (E) Pathogenic Y. pseudotuberculosis and EPEC use Type III secretion systems to inject Cifs into the cytosol of host cells where they deamidate Gln40 of NEDD8. The enzymatic conversion of Gln to Glu inactivates the CRL and thus prevents ubiquitin dependent intracellular trafficking of Perforin-2. N8, NEDD8; Ub, ubiquitin; CUL1, cullin 1.

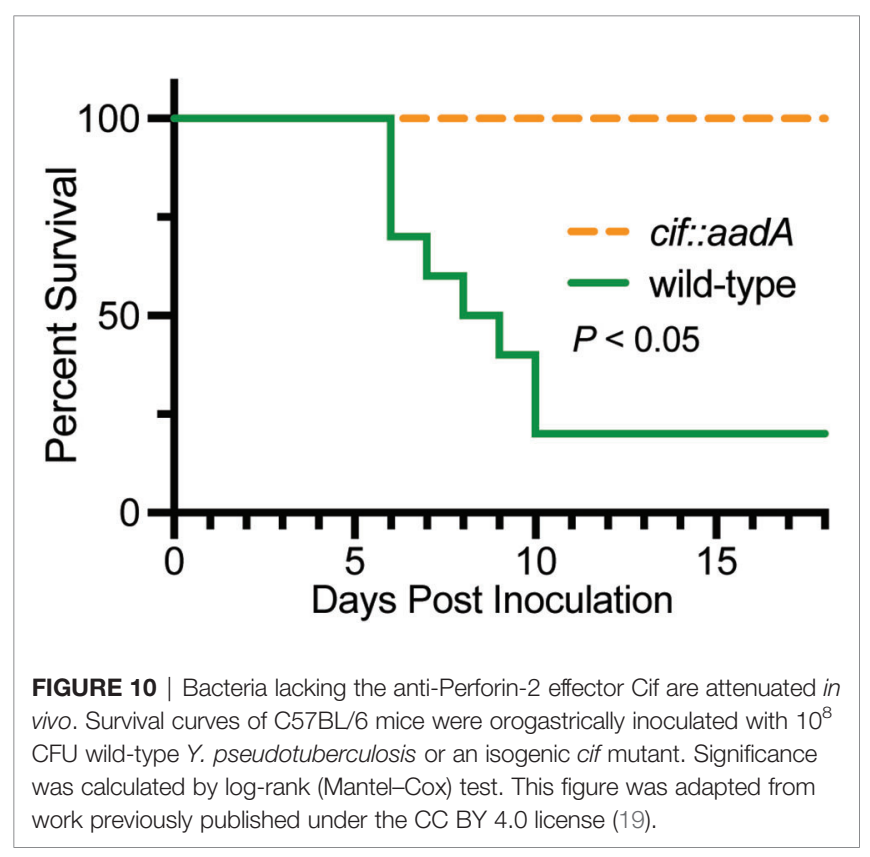

It is also not yet known if Perforin-2 can breach bacterial membranes by itself or if it requires the assistance of other host proteins. Our review and evaluation of the in vitro systems reported to date raises significant doubts that Perforin-2 dependent killing was actually observed with recombinant protein $(27,29-31,33,34,38,39,43)$. Our first major concern is that some researchers opted to purify the MACPF domain in the absence of the P2 domain (29, 31, 43). However, we now know that the P2 domain forms the outer ring of Perforin-2 polymers with extensive surface area packed between the two domains and neighboring subunits (Figure 3) $(20,21)$. Thus, it seems improbable that the MACPF domain of Perforin2 would polymerize in the absence of the P2 domain. In addition, there is evidence that the extended $\beta$-hairpin of the P2 domain mediates the initial interactions with target membranes (Figure 2) (20). Therefore, even if the MACPF domain does polymerize it is unclear how it would target bacterial membranes. We also note that all studies with recombinant Perforin-2 did not convincingly demonstrate bacterial killing $(27,29,31,34,43)$. Rather, most simply reported changes in the optical absorbance of bacterial cultures. As discussed below there is also the possibility that glycosylation is essential for Perforin-2 folding, polymerization, or pore formation/stabilization. These post-translational modifications would be absent in the studies that produced recombinant Perforin-2 or its MACPF in E. coli (27, 29, 31, 34, 43). Although claims of recombinant Perforin-2's bactericidal activity are to date unconvincing, the development of a technically sound in vitro bactericidal assay would be a substantial advance that would facilitate further mechanistic investigations. 
Among other outstanding questions is the necessity of posttranslational modifications; specifically, glycosylation. Two independent structural studies observed glycosylation of Asn 185 and Asn269 (20,21). These residues are conserved and glycosylated in both human and mouse Perforin-2. Despite their conservation it is not known if the glycans are required for protein stability/folding, oligomerization, or pore formation/ stabilization. Elucidating the functional and mechanistic consequences of Perforin-2 glycosylation may have clinical implications because missense mutations of both Asn185 and Ans269 are present within the human population (gnomAD, https://gnomad.broadinstitute.org/).

There are also significant gaps in our understanding of the intracellular trafficking of Perforin-2. Although it has been shown that ubiquitination of Perforin-2's cytosolic tail drives trafficking (19), the mechanism(s) of intracellular trafficking and delivery to the phagosome is largely unknown. Likewise, the linkage between PAMP/TLR signaling and ubiquitination is unclear. This may involve the activation of a kinase that phosphorylates the cytosolic tail of Perforin-2 prior to CRLdependent ubiquitination. However, this upstream pathway remains in the realm of the hypothetical.

Perforin-2 may also require proteolytic processing to release it from its transmembrane domain and facilitate subsequent polymerization. Indeed Perforin-2 fragments have been observed after cellular infection (15). Perhaps the cleavage products are relevant to polymerization and pore formation. Alternatively, they may be mechanistically insignificant degradation products. Although it is not yet known which of these two scenarios is correct, we and others suspect that tethering to a vacuolar membrane is inhibitory; preventing polymerization $(20,104,105)$. In our "safety tether" hypothesis Perforin-2 is maintained as a monomer as long as it exists as a Type I transmembrane protein. However we also note that there is evidence for Perforin-2 dependent autolysis under certain circumstances. For example, Eckhard Podack used negative stain transmission electron microscopy to image apparent Perforin-2 polymers with membrane preparations of HEK-293 cells engineered to overexpress Perforin-2-GFP (15). Of potential relevance to our safety tether hypothesis, Perforin-2 polymers were only observed after partial trypsin digest. Polymers were not observed with undigested preparations. More recently Hung et al. have shown that Perforin-2 is required for the release of IL-33 from dendritic cells (106). Because IL-33 lacks a signal peptide, the authors propose that Perforin-2 forms pores in the plasma membrane to release cytosolic IL-33. Although the supporting data is quite convincing, the study raises many mechanistic questions. For example, does Perforin-2 attack the plasma membrane from the exterior or interior of the cell? In either case does pore formation involve proteolytic cleavage and/ or low $\mathrm{pH}$ ? In addition there is no known mechanism for the selective gating of Perforin-2 pores. Therefore, it seems likely that IL-33 secreting dendritic cells would also release a plethora of cytosolic molecules. Is Perforin-2 autolysis ultimately lethal or is autolysis somehow mitigated to prevent lethality? Addressing these and other questions will provide greater understanding of
Perforin-2 functionality and may also identify novel clinical avenues that could be used to treat diseases associated with Perforin-2 deficiencies.

Although Perforin-2 research has made considerable progress from the perspective of the host, less is known about pathogen strategies to survive Perforin-2. To date, Cifs are the only class of anti-Perforin-2 effectors to be discovered. Given the persistence of Perforin-2 throughout diverse organisms, it is reasonable to expect that many other pathogenic countermeasures remain undiscovered. With sufficient interest progress in this area is possible and particularly suited to unbiased screens such as TnSeq. Once a candidate anti-Perforin-2 effector is identified, it can be thought of as a molecular probe that can elucidate the cellular and molecular mechanisms of Perforin-2 dependent killing. Of course, more passive survival strategies - such as alteration of the bacterial envelope or cell wall - are also possible. Despite numerous unknowns, it is clear that this field is poised for expansion and discovery.

\section{AUTHOR CONTRIBUTIONS}

LM, ZR, and GM developed the concept, critically reviewed the literature, and wrote various sections of the manuscript. GM was responsible for figure design and layout. All authors participated in the manuscript revision. All authors contributed to the article and approved the submitted version.

\section{FUNDING}

Perforin-2 research in the laboratory of GM is supported by the National Institute of Allergy and Infectious Diseases of the National Institutes of Health under award numbers R01AI110810 and R21AI156567. The content of this publication is solely the responsibility of the authors and does not necessarily represent the official views of the National Institutes of Health.

\section{ACKNOWLEDGMENTS}

The authors dedicate this publication to the memory of Eckhard R. Podack (1943-2015); the founder of Perforin-2 research and lead author of seminal studies in the field. Molecular graphics were rendered with UCSF Chimera or ChimeraX, developed by the Resource for Biocomputing, Visualization, and Informatics at the University of California, San Francisco, with support from the Office of Cyber Infrastructure and Computational Biology, National Institute of Allergy and Infectious Diseases, National Institutes of Health under award numbers P41GM103311 and R01GM129325 (107, 108). http://www.rbvi.ucsf.edu/chimera; https://www.cgl.ucsf. edu/chimerax 


\section{REFERENCES}

1. Lukoyanova N, Hoogenboom BW, Saibil HR. The membrane attack complex, perforin and cholesterol-dependent cytolysin superfamily of pore-forming proteins. J Cell Sci (2016) 129:2125-33. doi: 10.1242/ jcs. 182741

2. Ni T, Gilbert RJC. Repurposing a pore: Highly conserved perforin-like proteins with alternative mechanisms. Philos Trans R Soc B Biol Sci (2017) 372. doi: $10.1098 /$ rstb.2016.0212

3. Gilbert RJC. Pore-forming toxins. Cell Mol Life Sci (2002) 59:832-44. doi: 10.1007/s00018-002-8471-1

4. Anderluh G, Kisovec M, Kraševec N, Gilbert RJC. Distribution of MACPF/ CDC proteins. Subcell Biochem (2014) 80:7-30. doi: 10.1007/978-94-0178881-6_2

5. Yoshida A, Fukazawa M, Ushio H, Aiyoshi Y, Soeda S, Ito K. Study of cell kinetics in anaplastic thyroid carcinoma transplanted to nude mice. J Surg Oncol (1989) 41:1-4. doi: 10.1002/jso.2930410104

6. Gilbert RJC, Jiménez JL, Chen S, Tickle IJ, Rossjohn J, Parker M, et al. Two structural transitions in membrane pore formation by pneumolysin, the pore-forming toxin of Streptococcus pneumoniae. Cell (1999) 97:647-55. doi: 10.1016/S0092-8674(00)80775-8

7. Podack ER, Tschopp J. Polymerization of the ninth component of complement (C9): Formation of poly(C9) with a tubular ultrastructure resembling the membrane attack complex of complement. Proc Natl Acad Sci USA (1982) 79:574-8. doi: 10.1073/pnas.79.2.574

8. Morgan BP, Walters D, Serna M, Bubeck D. Terminal complexes of the complement system: new structural insights and their relevance to function. Immunol Rev (2016) 274:141-51. doi: 10.1111/imr.12461

9. Voskoboinik I, Whisstock JC, Trapani JA. Perforin and granzymes: Function, dysfunction and human pathology. Nat Rev Immunol (2015) 15:388-400. doi: 10.1038/nri3839

10. Law RHP, Lukoyanova N, Voskoboinik I, Caradoc-Davies TT, Baran K, Dunstone MA, et al. The structural basis for membrane binding and pore formation by lymphocyte perforin. Nature (2010) 468:447-51. doi: 10.1038/ nature09518

11. Dudkina NV, Spicer BA, Reboul CF, Conroy PJ, Lukoyanova N, Elmlund H, et al. Structure of the poly-C9 component of the complement membrane attack complex. Nat Commun (2016) 7:10588. doi: 10.1038/ncomms10588

12. Podack ER, Tschopp J. Circular polymerization of the ninth component of complement. Ring closure of the tubular complex confers resistance to detergent dissociation and to proteolytic degradation. J Biol Chem (1982). doi: $10.1073 /$ pnas.79.2.574

13. Spilsbury K, O'Mara MA, Wu WM, Rowe PB, Symonds G, Takayama Y. Isolation of a novel macrophage-specific gene by differential cDNA analysis. Blood (1995). doi: 10.1182/blood.v85.6.1620.bloodjournal8561620

14. Dangelo ME, Dunstone MA, Whisstock JC, Trapani JA, Bird PI. Perforin evolved from a gene duplication of MPEG1, followed by a complex pattern of gene gain and loss within Euteleostomi. BMC Evol Biol (2012) 12:59. doi: 10.1186/1471-2148-12-59

15. McCormack RM, de Armas LR, Shiratsuchi M, Fiorentino DG, Olsson ML, Lichtenheld MG, et al. Perforin-2 is essential for intracellular defense of parenchymal cells and phagocytes against pathogenic bacteria. eLife (2015) 4:1-29. doi: 10.7554/eLife.06508

16. Garin J, Diez R, Kieffer S, Dermine JF, Duclos S, Gagnon E, et al. The phagosome proteome: Insight into phagosome functions. J Cell Biol (2001) 4: e06508. doi: $10.1083 /$ jcb.152.1.165

17. Nakamura N, Lill JR, Phung Q, Jiang Z, Bakalarski C, De Mazière A, et al. Endosomes are specialized platforms for bacterial sensing and NOD2 signalling. Nature (2014). doi: 10.1038/nature13133

18. Duclos S, Clavarino G, Rousserie G, Goyette G, Boulais J, Camossetto V, et al. The endosomal proteome of macrophage and dendritic cells. Proteomics (2011) 11:854-64. doi: 10.1002/pmic.201000577

19. McCormack RM, Lyapichev K, Olsson ML, Podack ER, Munson GP. Enteric pathogens deploy cell cycle inhibiting factors to block the bactericidal activity of Perforin-2. eLife (2015) 4:e06505. doi: 10.7554/eLife.06505

20. Ni T, Jiao F, Yu X, Aden S, Ginger L, Williams SI, et al. Structure and mechanism of bactericidal mammalian perforin-2, an ancient agent of innate immunity. Sci $A d v$ (2020) 6:eaax8286. doi: 10.1126/sciadv.aax8286
21. Pang SS, Bayly-Jones C, Radjainia M, Spicer BA, Law RHP, Hodel AW, et al. The cryo-EM structure of the acid activatable pore-forming immune effector Macrophage-expressed gene 1. Nat Commun (2019). doi: 10.1038/s41467019-12279-2

22. Christie MP, Johnstone BA, Tweten RK, Parker MW, Morton CJ. Cholesterol-dependent cytolysins: from water-soluble state to membrane pore. Biophys Rev (2018). doi: 10.1007/s12551-018-0448-x

23. Tweten RK. Cholesterol-dependent cytolysins, a family of versatile poreforming toxins. Infect Immun (2005). doi: 10.1128/IAI.73.10.61996209.2005

24. Hackam DJ, Rotstein OD, Zhang WJ, Demaurex N, Woodside M, Tsai O, et al. Regulation of phagosomal acidification. Differential targeting of $\mathrm{Na}+\mathrm{H}+$ exchangers, $\mathrm{Na}+/ \mathrm{K}+$-ATPases, and vacuolar-type $\mathrm{H}+$-ATPases. J Biol Chem (1997). doi: $10.1074 / j b c .272 .47 .29810$

25. Beyenbach KW, Wieczorek H. The V-type H+ ATPase: Molecular structure and function, physiological roles and regulation. J Exp Biol (2006). doi: $10.1242 /$ jeb.02014

26. Bai F, McCormack RM, Hower S, Plano GV, Lichtenheld MG, Munson GP. Perforin-2 Breaches the Envelope of Phagocytosed Bacteria Allowing Antimicrobial Effectors Access to Intracellular Targets. J Immunol (2018) 201:2710-20. doi: 10.4049/jimmunol.1800365

27. Wiens M, Korzhev M, Krasko A, Thakur NL, Perović-Ottstadt S, Breter HJ, et al. Innate immune defense of the sponge Suberites domuncula against bacteria involves a MyD88-dependent signaling pathway: Induction of a perforin-like molecule. J Biol Chem (2005) 280:27949-59. doi: 10.1074/ jbc.M504049200

28. Walters BM, Connelly MT, Young B, Traylor-Knowles N. The Complicated Evolutionary Diversification of the Mpeg-1/Perforin-2 Family in Cnidarians. Front Immunol (2020) 11:1690. doi: 10.3389/fimmu.2020.01690

29. Choi KM, Cho DH, Joo MS, Choi HS, Kim MS, Han HJ, et al. Functional characterization and gene expression profile of perforin-2 in starry flounder (Platichthys stellatus). Fish Shellfish Immunol (2020) 107:511-8. doi: 10.1016/j.fsi.2020.11.011

30. Estévez-Calvar N, Romero A, Figueras A, Novoa B. Involvement of poreforming molecules in immune defense and development of the Mediterranean mussel (Mytilus galloprovincialis). Dev Comp Immunol (2011) 35:1017-31. doi: 10.1016/j.dci.2011.03.023

31. Bathige SDNK, Umasuthan N, Whang I, Lim BS, Won SH, Lee J. Antibacterial activity and immune responses of a molluscan macrophage expressed gene-1 from disk abalone, Haliotis discus discus. Fish Shellfish Immunol (2014) 39:263-72. doi: 10.1016/j.fsi.2014.05.012

32. Modak TH, Gomez-Chiarri M. Contrasting immunomodulatory effects of probiotic and pathogenic bacteria on eastern oyster, crassostrea virginica, larvae. Vaccines (2020) 8:588. doi: 10.3390/vaccines8040588

33. Kemp IK, Coyne VE. Identification and characterisation of the Mpeg1 homologue in the South African abalone, Haliotis midae. Fish Shellfish Immunol (2011) 31:754-64. doi: 10.1016/j.fsi.2011.07.010

34. Ni L, Han Q, Chen H, Luo X, Li A, Dan X. Grouper (Epinephelus coioides) Mpeg1s : Molecular identification, expression analysis, and antimicrobial activity. Fish Shellfish Immunol (2019) 92:690-7. doi: 10.1016/j.fsi.2019.06.060

35. Jagannathan-Bogdan M, Zon LI. Hematopoiesis. Dev (2013) 140:2463-7. doi: $10.1242 /$ dev.083147

36. Mo ZQ, Li YW, Wang HQ, Wang J, LY N, Yang M, et al. Comparative transcriptional profile of the fish parasite Cryptocaryon irritans. Parasites Vectors (2016) 9:1-12. doi: 10.1186/s13071-016-1919-1

37. Ni LY, Chen HP, Han R, Luo XC, Li AX, Li JZ, et al. Distribution of Mpeg1+ cells in healthy grouper (Epinephelus coioides) and after Cryptocaryon irritans infection. Fish Shellfish Immunol (2020) 104:222-7. doi: 10.1016/ j.fsi.2020.06.018

38. Le Pennec G, Gardères J. The challenge of the sponge suberites domuncula (Olivi, 1792) in the presence of a symbiotic bacterium and a pathogen bacterium. Genes (Basel) (2019). doi: 10.3390/genes10070485

39. Libro S, Kaluziak ST, Vollmer SV. RNA-seq profiles of immune related genes in the staghorn coral Acropora cervicornis Infected with white band disease. PLoS One (2013). doi: 10.1371/journal.pone.0081821

40. Gignoux-Wolfsohn SA, Vollmer SV. Identification of candidate coral pathogens on white band disease-infected staghorn coral. PLoS One (2015). doi: 10.1371/journal.pone.0134416 
41. Duke RC, Persechini PM, Chang S, Liu CC, Cohen JJ, Young JD. Purified perforin induces target cell lysis but not DNA fragmentation. J Exp Med (1989). doi: 10.1084/jem.170.4.1451

42. Masson D, Tschopp J. Isolation of a lytic, pore-forming protein (perforin) from cytolytic T-lymphocytes. J Biol Chem (1985) 260:9069-72.

43. He X, Zhang Y, Yu Z. An Mpeg (macrophage expressed gene) from the Pacific oyster Crassostrea gigas: Molecular characterization and gene expression. Fish Shellfish Immunol (2011) 30:870-6. doi: 10.1016/j.fsi.2011.01.009

44. Biesecker G, Muller-Eberhard HJ. The ninth component of human complement: Purification and physicochemical characterization. J Immunol (1980) 124:1291-6.

45. Biesecker G, Gerard C, Hugli TE. An amphiphilic structure of the ninth component of human complement. Evidence from analysis of fragments produced by $\alpha$-thrombin. J Biol Chem (1982).

46. Kontermann R, Rauterberg EW. N-Deglycosylation of human complement component C9 reduces its hemolytic activity. Mol Immunol (1989). doi: 10.1016/0161-5890(89)90056-4

47. Franc V, Yang Y, Heck AJR. Proteoform Profile Mapping of the Human Serum Complement Component C9 Revealing Unexpected New Features of N-, O-, and C-Glycosylation. Anal Chem (2017). doi: 10.1021/ acs.analchem.6b04527

48. Spicer BA, Law RHP, Caradoc-Davies TT, Ekkel SM, Bayly-Jones C, Pang SS, et al. The first transmembrane region of complement component- 9 acts as a brake on its self-assembly. Nat Commun (2018). doi: 10.1038/s41467018-05717-0

49. Chen R, Jiang X, Sun D, Han G, Wang F, Ye M, et al. Glycoproteomics analysis of human liver tissue by combination of multiple enzyme digestion and hydrazide chemistry. J Proteome Res (2009). doi: 10.1021/pr8008012

50. Shental-Bechor D, Levy Y. Effect of glycosylation on protein folding: A close look at thermodynamic stabilization. Proc Natl Acad Sci U S A (2008). doi: $10.1073 /$ pnas. 0801340105

51. Lee HS, Qi Y, Im W. Effects of N-glycosylation on protein conformation and dynamics: Protein Data Bank analysis and molecular dynamics simulation study. Sci Rep (2015) 5:8926. doi: 10.1038/srep08926

52. McCormack R, Bahnan W, Shrestha N, Boucher J, Barreto M, Barrera CM, et al. Perforin-2 Protects Host Cells and Mice by Restricting the Vacuole to Cytosol Transitioning of a Bacterial Pathogen. Infect Immun (2016) 84:1083-91. doi: 10.1128/iai.01434-15

53. McCormack R, De Armas LR, Shiratsuchi M, Ramos JE, Podack ER. Inhibition of intracellular bacterial replication in fibroblasts is dependent on the perforin-like protein (Perforin-2) encoded by macrophage-expressed gene 1. J Innate Immun (2013) 5:185-94. doi: 10.1159/000345249

54. Strbo N, Pastar I, Romero L, Chen V, Vujanac M, Sawaya AP, et al. Single cell analyses reveal specific distribution of anti-bacterial molecule Perforin-2 in human skin and its modulation by wounding and Staphylococcus aureus infection. Exp Dermatol (2019) 28:225-32. doi: 10.1111/exd.13870

55. Ellett F, Pase L, Hayman JW, Andrianopoulos A, Lieschke GJ. Phagocytes, Granulocytes, and Myelopoiesis mpeg1 promoter transgenes direct macrophage-lineage expression in zebrafish. Blood (2011) 27:e49-56. doi: 10.1182/blood-2010-10-314120

56. Zakrzewska A, Cui C, Stockhammer OW, Benard EL, Spaink HP, Meijer AH. Macrophage-specific gene functions in Spil-directed innate immunity. Blood (2010) 116:1-12. doi: 10.1182/blood-2010-01-262873

57. Benard EL, Racz PI, Rougeot J, Nezhinsky AE, Verbeek FJ, Spaink HP, et al. Macrophage-expressed perforins Mpeg1 and Mpeg1.2 have an anti-bacterial function in zebrafish. I Innate Immun (2015) 7:136-52. doi: 10.1159/ 000366103

58. Mostowy S, Boucontet L, Mazon Moya MJ, Sirianni A, Boudinot P, Hollinshead M, et al. The Zebrafish as a New Model for the In Vivo Study of Shigella flexneri Interaction with Phagocytes and Bacterial Autophagy. PLoS Pathog (2013) 9:e81003588. doi: 10.1371/journal.ppat.1003588

59. McCormack RM. Elucidating Perforin-2 Mediated Killing Mechanisms Against Pathogenic Bacteria. (2017). Available at: https://scholarship. miami.edu/discovery/fulldisplay/alma991031447876202976/01UOML_ INST:ResearchRepository?lang=en.

60. McCormack R, Podack ER. Perforin-2/Mpeg1 and other pore-forming proteins throughout evolution. J Leukoc Biol (2015) 98:761-8. doi: $10.1189 /$ jlb.4MR1114-523RR
61. Podack ER, Munson GP. Killing of microbes and cancer by the immune system with three mammalian pore-forming killer proteins. Front Immunol (2016) 7:464. doi: 10.3389/fimmu.2016.00464

62. Podack ER, Kolb WP, Muller-Eberhard HJ. The SC5b-7 complex: Formation, isolation, properties, and subunit composition. J Immunol (1977).

63. Podack ER, Esser AF, Biesecker G, Muller-Eberhard HJ. Membrane attack complex of complement. A structural analysis of its assembly. J Exp Med (1980). doi: 10.1084/jem.151.2.301

64. Tschopp J, Podack ER. Membranolysis by the ninth component of human complement. Biochem Biophys Res Commun (1981). doi: 10.1016/0006-291X (81)91981-1

65. Tschopp J, Müller-Eberhard HJ, Podack ER. Formation of transmembrane tubules by spontaneous polymerization of the hydrophilic complement protein C9. Nature (1982). doi: 10.1038/298534a0

66. Podack ER, Dennert G. Assembly of two types of tubules with putative cytolytic function by cloned natural killer cells. Nature (1983). doi: 10.1038/ $302442 \mathrm{a} 0$

67. Podack ER, Konigsberg PJ, Acha-Orbea H, Pircher H, Hengartner H. Cytolytic T-cell granules: biochemical properties and functional specificity. Adv Exp Med Biol (1985). doi: 10.1007/978-1-4684-8326-0_8

68. Podack ER, Young JDE, Cohn ZA. Isolation and biochemical and functional characterization of perforin 1 from cytolytic T-cell granules. Proc Natl Acad Sci U S A (1985). doi: 10.1073/pnas.82.24.8629

69. Lichtenheld MG, Olsen KJ, Lu P, Lowrey DM, Hameed A, Hengartner H, et al. Structure and function of human perforin. Nature (1988). doi: 10.1038/ $335448 \mathrm{a} 0$

70. Podack ER, Hengartner H. Structure of perforin and its role in cytolysis. Year Immunol (1989).

71. McCormack R, De Armas L, Shiratsuchi M, Podack ER. Killing machines: Three pore-forming proteins of the immune system. Immunol Res (2013) 57:268-78. doi: 10.1007/s12026-013-8469-9

72. Fields KA, McCormack R, de Armas LR, Podack ER. Perforin-2 Restricts Growth of Chlamydia trachomatis in Macrophages. Infect Immun (2013) 81:3045-54. doi: 10.1128/iai.00497-13

73. Darville T, Hiltke TJ. Pathogenesis of genital tract disease due to Chlamydia trachomatis. J Infect Dis (2010) 201:114-25. doi: 10.1086/652397

74. Keb G, Fields KA. An Ancient Molecular Arms Race: Chlamydia vs. Membrane Attack Complex/Perforin (MACPF) Domain Proteins. Front Immunol (2020). doi: 10.3389/fimmu.2020.01490

75. Pastar I, O’Neill K, Padula L, Head CR, Burgess JL, Chen V, et al. Staphylococcus epidermidis Boosts Innate Immune Response by Activation of Gamma Delta T Cells and Induction of Perforin-2 in Human Skin. Front Immunol (2020) 11:550946. doi: 10.3389/ fimmu.2020.550946

76. Gayle P, McGaughey V, Hernandez R, Wylie M, Colletti RC, Nguyen KL, et al. Maternal- and Fetal-Encoded Perforin-2 Limits Placental Infection by a Bloodborne Pathogen. J Immunol (2020) 205:1878-85. doi: 10.4049/ jimmunol.2000615

77. Cheers C, Wood P. Listeriosis in beige mice and their heterozygous littermates. Immunology (1984) 51:711-7.

78. Portnoy DA, Auerbuch V, Glomski IJ. The cell biology of Listeria monocytogenes infection: The intersection of bacterial pathogenesis and cell-mediated immunity. J Cell Biol (2002). doi: 10.1083/jcb. 200205009

79. Dramsi S, Cossart P. Listeriolysin O: A genuine cytolysin optimized for an intracellular parasite. J Cell Biol (2002). doi: 10.1083/jcb.200202121

80. McCormack R, Hunte R, Podack ER, Plano GV, Shembade N. An Essential Role for Perforin-2 in Type I IFN Signaling. J Immunol (2020). doi: 10.4049/ jimmunol.1901013

81. Merselis LC, Munson GP. Perforin-2 (MPEG1) knockout mice are not resistant to LPS induced septic shock. figshare (2020). doi: 10.6084/ m9.figshare.12652829.v2

82. Kayagaki N, Warming S, Lamkanfi M, Vande Walle L, Louie S, Dong J, et al. Non-canonical inflammasome activation targets caspase-11. Nature (2011). doi: 10.1038/nature10558

83. Kenneth NS, Younger JM, Hughes ED, Marcotte D, Barker PA, Saunders TL, et al. An inactivating caspase 11 passenger mutation originating from the 
129 murine strain in mice targeted for c-IAP1. Biochem J (2012). doi: 10.1042/BJ20120249

84. McCormack RM, Munson GP. Perforin-2 (MPEG1) is not required for Type I Interferon signaling. figshare (2020). doi: 10.6084/m9.figshare.12654014.v1

85. Thomas C, Moraga I, Levin D, Krutzik PO, Podoplelova Y, Trejo A, et al. Structural linkage between ligand discrimination and receptor activation by Type I interferons. Cell (2011). doi: 10.1016/j.cell.2011.06.048

86. Weng G, Wang E, Wang Z, Liu H, Zhu F, Li D, et al. HawkDock: a web server to predict and analyze the protein-protein complex based on computational docking and MM/GBSA. Nucleic Acids Res (2019). doi: 10.1093/nar/gkz397

87. Ringwald M, Eppig JT, Kadin JA, Richardson JE, Begley DA, Corradi JP, et al. GXD: A gene expression database for the laboratory mouse: Current status and recent enhancements. Nucleic Acids Res (2000). doi: 10.1093/nar/ 28.1.115

88. Hemberger M, Himmelbauer H, Ruschmann J, Zeitz C, Fundele R. cDNA subtraction cloning reveals novel genes whose temporal and spatial expression indicates association with trophoblast invasion. Dev Biol (2000). doi: 10.1006/dbio.2000.9705

89. Karczewski KJ, Francioli LC, Tiao G, Cummings BB, Alföldi J, Wang Q, et al. The mutational constraint spectrum quantified from variation in 141,456 humans. Nature (2020) 581:434-43. doi: 10.1038/s41586-020-2308-7

90. McCormack RM, Szymanski EP, Hsu AP, Perez E, Olivier KN, Fisher E, et al. MPEG1/perforin-2 mutations in human pulmonary nontuberculous mycobacterial infections. JCI Insight (2017) 2:1-8. doi: 10.1172/ jci.insight. 89635

91. Merselis LC, Jiang SYUndiagnosed Diseases Network, , Nelson SF, Lee H, Prabaker KK, et al. MPEG1/Perforin-2 Haploinsufficiency Associated Polymicrobial Skin Infections and Considerations for Interferon- $\gamma$ Therapy. Front Immunol (2020) 11:601584. doi: 10.3389/fimmu.2020. 601584

92. Bosu DR, Kipreos ET. Cullin-RING ubiquitin ligases: Global regulation and activation cycles. Cell Div (2008). doi: 10.1186/1747-1028-3-7

93. Cardozo T, Pagano M. The SCF ubiquitin ligase: Insights into a molecular machine. Nat Rev Mol Cell Biol (2004). doi: 10.1038/nrm1471

94. Charpentier X, Oswald E. Identification of the secretion and translocation domain of the enteropathogenic and enterohemorrhagic Escherichia coli effector Cif, using TEM-1 $\beta$-lactamase as a new fluorescence-based reporter. J Bacteriol (2004). doi: 10.1128/JB.186.16.5486-5495.2004

95. Crow A, Hughes RK, Taieb F, Oswald E, Banfield MJ. The molecular basis of ubiquitin-like protein NEDD8 deamidation by the bacterial effector protein Cif. Proc Natl Acad Sci U S A (2012) 109:1830-8. doi: 10.1073/pnas. 1112107109

96. Cui J, Yao Q, Li S, Ding X, Lu Q, Mao H, et al. Glutamine deamidation and dysfunction of ubiquitin/NEDD8 induced by a bacterial effector family. Science (2010) 80:1215-8. doi: 10.1126/science.1193844
97. Reddick LE, Alto NM. Bacteria fighting back: How pathogens target and subvert the host innate immune system. Mol Cell (2014) 54:321-8. doi: 10.1016/j.molcel.2014.03.010

98. Wilkinson CR, Garrone R, Vacelet J. Marine sponges discriminate between food bacteria and bacterial symbionts: Electron microscope radioautography and in situ evidence. Proc R Soc London - Biol Sci (1984). doi: 10.1098/ rspb.1984.0018

99. Wehrl M, Steinert M, Hentschel U. Bacterial uptake by the marine sponge Aplysina aerophoba. Microb Ecol (2007). doi: 10.1007/s00248-006-9090-4

100. Olano CT, Bigger CH. Phagocytic activities of the gorgonian coral Swiftia exserta. J Invertebr Pathol (2000). doi: 10.1006/jipa.2000.4974

101. Adema CM, Vanderknaap WPW, Sminia T. Molluscan Hemocyte-Mediated Cytotoxicity - the Role of Reactive Oxygen Intermediates. Rev Aquat Sci (1991).

102. Mohandas A, Cheng TC, Cheng JB. Mechanism of lysosomal enzyme release from Mercenaria mercenaria granulocytes: A scanning electron microscope study. J Invertebr Pathol (1985). doi: 10.1016/0022-2011(85)90148-X

103. Willenz P, Van de Vyver G. Ultrastructural localization of lysosomal digestion in the fresh water sponge Ephydatia fluviatilis. $J$ Ultrasructure Res (1984). doi: 10.1016/S0022-5320(84)90112-6

104. Krawczyk PA, Laub M, Kozik P. To Kill But Not Be Killed: Controlling the Activity of Mammalian Pore-Forming Proteins. Front Immunol (2020). doi: 10.3389/fimmu.2020.601405

105. Bayly-Jones C, Pang SS, Spicer BA, Whisstock JC, Dunstone MA. Ancient but Not Forgotten: New Insights Into MPEG1, a Macrophage Perforin-Like Immune Effector. Front Immunol (2020). doi: 10.3389/fimmu.2020.581906

106. Hung LY, Tanaka Y, Herbine K, Pastore C, Singh B, Ferguson A, et al. Cellular context of IL-33 expression dictates impact on anti-helminth immunity. Sci Immunol (2020). doi: 10.1126/sciimmunol.abc6259

107. Pettersen EF, Goddard TD, Huang CC, Couch GS, Greenblatt DM, Meng EC, et al. UCSF Chimera - A visualization system for exploratory research and analysis. J Comput Chem (2004). doi: 10.1002/jcc.20084

108. Pettersen EF, Goddard TD, Huang CC, Meng EC, Couch GS, Croll TI, et al. UCSF ChimeraX: Structure visualization for researchers, educators, and developers. Protein Sci (2020) 30:70-82. doi: 10.1002/pro.3943

Conflict of Interest: The authors declare that the research was conducted in the absence of any commercial or financial relationships that could be construed as a potential conflict of interest.

Copyright (c) 2021 Merselis, Rivas and Munson. This is an open-access article distributed under the terms of the Creative Commons Attribution License (CC BY). The use, distribution or reproduction in other forums is permitted, provided the original author(s) and the copyright owner(s) are credited and that the original publication in this journal is cited, in accordance with accepted academic practice. No use, distribution or reproduction is permitted which does not comply with these terms. 